\title{
Uma análise do conteúdo de transformações geométricas em livros didáticos do Ensino Médio
}

\author{
An analysis of the content of geometric transformations in High School \\ textbooks
}

Paulo Henrique Souza Nakamura

Vinícius Pazuch

\begin{abstract}
Resumo: Este artigo apresenta uma análise do conteúdo de transformações geométricas em três coleções de livros didáticos de Matemática para o Ensino Médio selecionadas pelo último Programa Nacional do Livro Didático (PNLD). Nesta análise, buscou-se identificar de que maneira as transformações geométricas de translação, reflexão, rotação e homotetia são apresentadas, como são as tarefas propostas sobre o conteúdo e as atribuições destinadas aos professores que utilizam esses livros. As análises foram constituídas a partir das noções teóricas de tarefa, incluindo exercício e problema. Constatou-se a falta de aprofundamento em algumas unidades dos livros analisadas, a ausência de um número expressivo de problemas, em vez de exercícios, e a escassez de sugestões para uma atuação mais significativa do conteúdo pelos professores no Ensino Médio.
\end{abstract}

Palavras-chave: Matemática. Transformações geométricas. Livros didáticos.

Abstract: This article presents an analysis of the content of geometric transformations in three collections of mathematics textbooks for high school selected by the last Programa Nacional do Livro Didático (PNLD). In this analysis, we sought to identify how the geometric transformations of translation, reflection, rotation and homotetia are presented, what are the tasks proposed on the content and the assignments for teachers who use these books. The analyzes were constituted from literature review of task, including problem situation, and exercise. It was found that there was a lack of deepening in some units of the analyzed books, the absence of a significant number of problems instead of exercises and the scarcity of suggestions for a more significant teacher's performance at High School.

Keywords: Mathematics. Geometric transformations. Textbooks.
Paulo Henrique Souza Nakamura Aluno da Licenciatura em Matemática pela Universidade Federal do ABC (UFABC). São Paulo, Brasil.

iD orcid.org/0000-0003-3620-7196 $\triangle$ paul0160600@gmail.com

Vinícius Pazuch Doutor em Ensino de Ciências e Matemática. Professor do Programa de Pós-Graduação em Ensino, História e Filosofia das Ciências e Matemática da Universidade Federal do ABC (UFABC). São Paulo, Brasil. iD orcid.org/0000-0001-6997-1110 $\bowtie$ vinicius.pazuch@ufabc.edu.br

Recebido em 07/07/2020 Aceito em 12/07/2020 Publicado em 17/11/2020

1 História e importância do livro didático de matemática e as transformações geométricas

Atualmente, o livro didático é a principal fonte que traduz determinações curriculares à prática do professor e, consequentemente, apresenta-se como a principal ferramenta para 0 desenvolvimento das aulas (LIMA e JANUARIO, 2017). Segundo Silva (2010), ele possui múltiplas dimensões, que podem ser sintetizadas na Figura 1. 


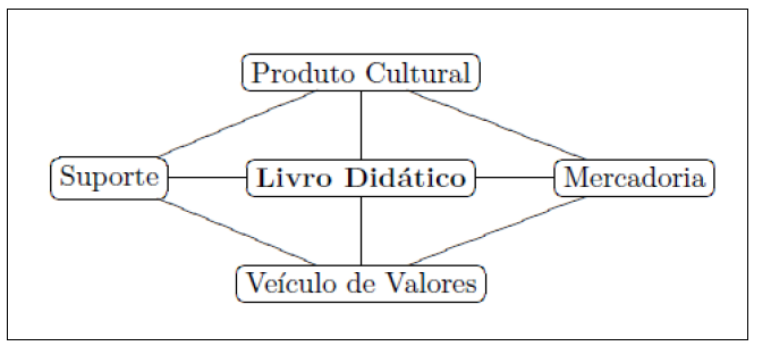

Figura 1: Dimensões do livro didático (SILVA, 2010, p. 21)

Para uma compreensão mais especializada de cada uma dessas dimensões, é importante considerar a história do livro didático. Nela, evidencia-se a sua origem, sobretudo, como veículo de comunicação entre as pessoas da comunidade escolar. Posteriormente, são incorporados os papéis de suporte de conhecimentos e metodologias e de mercadoria. Em todo seu percurso, esse instrumento nunca deixa de ser um produto cultural, reflexo da conjuntura em que foi escrito (SILVA, 2010).

De acordo com Zilberman (2003), a origem dos livros didáticos encontra-se na Europa, em meados do século XVII, no contexto de livros infantis, numa época em que a concepção da infância como "uma faixa etária diferenciada, com interesses próprios e necessitando de uma formação específica" (p. 44), começava a ser formada. Esses livros tinham mais caráter pedagógico do que literário e eram utilizados para educar moralmente as crianças, o que os configurava como veículos de valores.

Ao mesmo tempo em que esses livros começaram a ser escritos, a proliferação de colégios criados pelo poder civil com o apoio de instituições religiosas - motivadas pela rixa entre a Igreja Católica e a Reforma Protestante - tornava mais acentuada a necessidade por livros didáticos. Em particular, a educação católica - diga-se de passagem, a única atuante no Brasil de 1549 a 1759 - era ministrada pelos colégios jesuíticos, balizados por um documento chamado Ratio Studiorum. Esse documento expressava recomendações sobre as leituras que os estudantes deveriam fazer, incluindo, na parte de Matemática, o clássico Os Elementos, de Euclides. Essa recomendação foi duramente criticada, ainda no século $\mathrm{XVI}$, por um pedagogo francês chamado Petrus Ramus (1515-1572), por considerar a obra carente de metodologia. Ramus defendia que o estudo da Matemática deveria começar pela Aritmética - a seu ver, a parte mais geral da disciplina -, e não pela Geometria. Ele é considerado o primeiro a tecer reflexões sobre o método dos livros didáticos (SILVA, 2010). Contudo, de acordo com Boyer (1974), as tentativas de Ramus em reformar Os Elementos foram frustradas, em virtude de seus conhecimentos limitados sobre Geometria. 
De qualquer maneira, Ramus exerceu forte influência em muitos autores. É o caso do também francês Antoine Arnauld (1612-1694), que publicou o ousado Nouveaux Éléments de Géométrie. A obra foi tida como o primeiro livro didático de Matemática no sentido moderno. Escrita em vernáculo, tecia críticas ao clássico de Euclides e expunha a Álgebra antes da Geometria (SILVA, 2010).

O século XVIII consagrou esse novo paradigma de livro didático com a ascensão do lluminismo e da Enciclopédia. O lluminismo foi um movimento que defendia as liberdades individuais e o acesso à educação e à leitura como um requisito indispensável para esse fim. Nesse sentido, vários filósofos iluministas juntaram esforços para escrever a Enciclopédia grande obra que reunia conhecimentos de todas as áreas daquele período. Ela permitiu que, pela primeira vez, o conhecimento da época estivesse ao alcance do público em geral. Outro avanço desse período foi dado por Clairaut (1713-1765), que partia da premissa de não intimidar os estudantes (SILVA, 2010). Encarregado de educar a marquesa Émilie du Châtelet, que viria a se tornar uma brilhante cientista, Clairaut escreveu seu Éléments de Géométrie (BOYER, 1974), um dos primeiros livros contendo aplicações práticas da Matemática. Nessa altura, os livros didáticos já haviam se consolidado como suporte de conhecimentos e metodologias e, ademais, como mercadorias, haja vista que algumas editoras já existiam e comercializavam esses produtos.

Além de contribuir com a qualidade dos livros da época, as ideias liberais do lluminismo também fomentaram o desenvolvimento do capitalismo. A partir da segunda metade do século $\mathrm{XVIII,} \mathrm{ocorreram} \mathrm{mudanças} \mathrm{profundas} \mathrm{na} \mathrm{sociedade,} \mathrm{com} \mathrm{o} \mathrm{surgimento} \mathrm{de} \mathrm{novas} \mathrm{classes} \mathrm{sociais,}$ relações de trabalho e modos de produção. A industrialização requeria um número cada vez maior de trabalhadores aptos, o que favoreceu a abertura das escolas primárias para a população pobre. Desde então, novas concepções liberais da educação acompanham a evolução do capitalismo (SILVA, 2010).

No Brasil, em particular, Saviani (2013) propõe a seguinte periodização das ideias pedagógicas: de 1549 a 1759, Ensino religioso tradicional; de 1759 a 1932, Convívio entre os ensinos tradicionais religioso e leigo; de 1932 a 1969, Predomínio da pedagogia nova; de 1969 a 2001, Pedagogia produtivista.

Na pedagogia produtivista, destaca-se a vertente tecnicista. A influência do tecnicismo se estende até os dias de hoje; essa concepção, inspirada no processo fabril, caracteriza-se pela objetividade do ensino. Diferentemente da pedagogia tradicional, que se centra no professor, e da 
pedagogia nova, que tem como foco o aluno, o tecnicismo prioriza a competência em reproduzir a técnica. No caso particular da Matemática, preza-se pela memorização, pela aplicação de algoritmos e pela resolução de exercícios padrão.

O tecnicismo tem profundas implicações para os livros didáticos. Nessa concepção, os livros são escritos por um especialista alheio à realidade das salas de aula. Procura-se fazer livros completos e "autossuficientes", que diminuam o trabalho do professor. Isso vai ao encontro do plano produtivista: alcançar o máximo de resultados com o menor dispêndio possível, seja economizando o investimento na formação dos professores, seja contratando menos docentes em qualquer caso, confiando os resultados dos alunos aos livros didáticos. Isso redundou num quadro de "abuso" dos livros em muitas escolas, ou seja,

para uma boa parcela dos professores brasileiros, o livro didático se apresenta como uma insubstituível muleta. Na sua falta ou ausência, não se caminha cognitivamente na medida em que não há substância para ensinar. Coxos por formação e/ou mutilados pelo ingrato dia-a-dia do magistério, resta a esses professores engolir e reproduzir a ideia de que sem a adoção do livro didático não há como orientar a aprendizagem. (SILVA, 1996, p. 11).

Tendo essa conjuntura em vista, o presente artigo propõe-se a analisar livros de Matemática destinados ao Ensino Médio, aprovados pelo último Programa Nacional do Livro Didático (PNLD) - programa do Ministério da Educação responsável por avaliar e disponibilizar livros didáticos para escolas públicas em todo território nacional -, no tocante a um conteúdo específico: as transformações geométricas (translação, reflexão, rotação e homotetia). Esse assunto foi escolhido levando em consideração sua relevância na educação básica, na medida em que

as transformações geométricas permitem a introdução e a visualização de conceitos como números e medidas, percepção de semelhanças e diferenças e de regularidades ou não entre diversas estruturas, sem a necessidade de realizar sua definição formal prévia. Portanto, contribuem para o desenvolvimento da percepção visual do estudante. (DELMONDI e PAZUCH, 2018, p. 661)

A importância das transformações geométricas garantiu o lugar desse conteúdo na Base Nacional Comum Curricular (BNCC), que estabelece, na competência EM13MAT105, pela qual os alunos do Ensino Médio devem ser capacitados a

utilizar as noções de transformações isométricas (translação, reflexão, rotação e composições destas) e transformações homotéticas para construir figuras e analisar elementos da natureza e diferentes produções humanas (fractais, construções civis, 
Estudos teóricos relativos ao ensino de transformações geométricas (DELMONDI e PAZUCH, 2018), por meio de uma revisão sistemática da literatura, têm evidenciado lacunas na formação do professor que ensina Matemática e no conhecimento dos professores e dos estudantes. Delmondi e Pazuch (2018) identificam que a utilização da Geometria Dinâmica na abordagem do conteúdo de transformações geométricas pode ampliar as possibilidades de visualização e de compreensão por parte dos professores e estudantes. Há iniciativas de formação continuada com o uso de tecnologias digitais. Uma dessas iniciativas é o estudo de Oliveira e Lima (2018), em que professores aprimoraram os conhecimentos e estratégias didáticas sobre homotetias com tecnologias digitais.

Tomando como referência que há lacunas no conhecimento dos professores e dos estudantes sobre o conteúdo de transformações geométricas, procurou-se examinar como as transformações geométricas são abordadas em livros didáticos do Ensino Médio. Foram observados os capítulos referentes a: funções e gráficos, matrizes e números complexos. Analisou-se como são propostos os exercícios e problemas e as relações com o papel do professor nesse processo.

\section{Procedimentos metodológicos e aspectos analíticos}

Foram examinadas três coleções de livros destinadas ao Ensino Médio, cada qual composta por três volumes (Quadro 1). Essas coleções foram escolhidas segundo o PNLD e por estarem em uso nas escolas públicas do Estado de São Paulo, por professores do Ensino Médio.

Quadro 1: Livros analisados

\begin{tabular}{|c|c|c|c|}
\hline Título & Autor(es) & Editora & Ano \\
\hline \#Contato matemática & Joamir Souza e Jacqueline Garcia & FTD & 2016 \\
\hline $\begin{array}{c}\text { Matemática: ciência e } \\
\text { aplicações }\end{array}$ & $\begin{array}{c}\text { Gelson lezzi, Osvaldo Dolce, David } \\
\text { Degenszajn, Roberto Périgo e Nilze de } \\
\text { Almeida }\end{array}$ & Saraiva & 2016 \\
\hline $\begin{array}{c}\text { Matemática: Contexto \& } \\
\text { Aplicações }\end{array}$ & Luiz Roberto Dante & Ática & 2017 \\
\hline
\end{tabular}

Fonte: Dados da Pesquisa

A análise foi realizada diretamente na versão do professor de cada coleção, o que 
possibilitou o acesso aos comentários dos autores dos livros didáticos destinados aos docentes.

Para uniformizar a análise, foram levantados os conteúdos de ocorrência das transformações geométricas, chegando-se às seguintes unidades de análise: funções e gráficos, matrizes e números complexos. Em seguida, realizou-se, em cada coleção contemplada pela pesquisa, a busca das transformações geométricas nos capítulos referentes a esses conteúdos. A análise dos capítulos baseou-se no entendimento de que a Matemática é uma construção humana, oriunda de diversas sociedades e culturas e, portanto, é desejável que os livros didáticos proporcionem o contato dos alunos com a diversidade dentro de um processo de enculturação, isto é, de inserção do indivíduo na cultura Matemática. Isso inclui o estudo de simetrias presentes na arquitetura, na escultura, na pintura, no artesanato, entre outras criações humanas (LIMA e JANUARIO, 2017).

Em relação à análise das tarefas propostas nos livros analisados pela pesquisa, adotouse a distinção entre exercício e problema presente em Echeverría e Pozo (1998). Nessa concepção, exercício é uma tarefa objetiva, em que o aluno já detém o mecanismo resolutivo, bastando aplicá-lo para obter a solução; por outro lado, problema é uma tarefa mais complexa, em que a pessoa que tenta resolvê-la encontra alguma dificuldade que a obrigue a questionar-se sobre quais passos precisa seguir para alcançar o objetivo. Convém salientar que existem outras nomenclaturas encontradas na literatura, como a de George Polya, que utiliza "problemas rotineiros" e "problemas não-rotineiros" em lugar de "exercícios" e "problemas" (BROLEZZI, 2013). Polya, citado por Stanic e Kilpatrick (1990) ainda observa que,

embora problemas rotineiros possam ser usados para satisfazer certas funções pedagógicas de ensinar alunos a seguir um procedimento específico ou usar uma definição corretamente, apenas através do uso criterioso de problemas não-rotineiros é que os alunos podem desenvolver sua habilidade de resolução de problemas. (STANIC e KILPATRICK 1990 apud BROLEZZI, 2013, p. 44)

Além disso, Allevato e Onuchic (2019) destacam haver diferentes abordagens possíveis sobre a resolução de problemas na escola, a saber: ensinar sobre, para e através da resolução de problemas. A primeira abordagem considera a resolução de problemas como um novo conteúdo a ser tratado nas aulas, dando ênfase nas heurísticas, regras e procedimentos gerais independentes da área trabalhada - portanto, não enfatiza a resolução de problemas especificamente matemáticos. Já o ensino para a resolução de problemas consiste em orientar os alunos a aplicar os conhecimentos matemáticos teóricos aprendidos nas aulas em problemas 
concretos.

Allevato e Onuchic (2019, p. 36) advertem que "um perigo dessa concepção é que ela configure a resolução de problemas como uma atividade que os alunos só podem realizar após a introdução de um novo conceito, ou após o treino de alguma habilidade ou de algum algoritmo" Finalmente, no ensino de Matemática através da resolução de problemas, os problemas são utilizados como mobilização ao que será estudado. Nesse sentido, considera-se que a abordagem nos livros didáticos em que os problemas são usados no sentido de mobilização pode ser uma estratégia a ser utilizada pelo professor em sala de aula. No próximo tópico, passa-se a discutir as unidades de análise delimitadas para este estudo.

\section{Funções e gráficos}

De modo geral, a primeira série do Ensino Médio é dedicado ao estudo das funções afim, modular, quadrática, exponencial e logarítmica. Já na segunda série, são apresentadas as funções trigonométricas (seno, cosseno, tangente etc.). Muitas vezes, o gráfico de uma função pode ser obtido tomando o gráfico de uma função mais simples e modificando-o com translações, reflexões, rotações ou homotetias.

A seguir será apresentado a organização e estrutura dos livros didáticos analisados neste artigo de acordo com a unidade de análise: funções e gráficos.

No volume 1 da coleção \#Contato Matemática, são apresentadas as funções afim, quadrática, exponencial, logarítmica e modular. Os autores mencionam a transformação de translação no estudo das funções afim e modular. Também indicam que o gráfico da inversa de uma função bijetora pode ser obtido pela reflexão do gráfico da função original em relação à reta $y=x$. Em particular, essa observação é feita ao tratar das funções exponencial e logarítmica.

Já no volume 2 dessa coleção, os autores apresentam um roteiro para traçar os gráficos das funções generalizadas $a+b \cdot \operatorname{sen}(c x+d)$ e $a+b \cdot \cos (c x+d)$ a partir dos gráficos das funções $y=\operatorname{sen} x$ e $y=\cos x$, respectivamente. Para tanto, eles estudam a influência dos parâmetros $a, b, c$ e $d$ sobre os gráficos das funções mais simples.

As funções do tipo trigonométricas $f(x)=a+b \cdot \operatorname{sen}(c x+d)$ e $g(x)=a+b$. $\cos (c x+d)$ têm características semelhantes a $f(x)=\operatorname{sen} x$ e $g(x)=\cos x$, respectivamente. As constantes $a, b, c$ e $d$ estão relacionadas a essas características da seguinte maneira: 
A constante $a$ translada o gráfico da função em $|a|$ unidades para cima se $a>0$, ou para baixo se $a<0$. A constante $a$ altera a imagem da função.

A constante $b$ amplia verticalmente 0 gráfico da função se $|b|>1$ e comprime verticalmente se $|b|<1$. A constante $b$ altera a imagem da função.

A constante $c$ amplia o período da função se $|c|<1$ e comprime se $|c|>1$, com 0 novo período $p=\frac{p_{f}}{|c|}$ sendo $p_{f}$ o período da função trigonométrica correspondente.

A constante $d$ translada o gráfico da função em $\left|\frac{d}{c}\right|$ unidades para a esquerda se $\frac{d}{c}>$ 0 , ou para a direita se $\frac{d}{c}<0$. (GARCIA e SOUZA, 2016a, p. 29)

Nessa explicação, os autores não mencionam softwares de Geometria Dinâmica, que poderiam ampliar a possibilidade de visualização dos papeis dos parâmetros pelos estudantes. Em seguida, no livro, são propostos alguns exercícios e problemas sobre o conteúdo.

Quanto à coleção Matemática: ciência e aplicações, as transformações geométricas estão bastante presentes no segundo volume, principalmente no capítulo 4 , onde os autores ensinam a traçar o gráfico de duas funções trigonométricas $-f(x)=\operatorname{sen} x$ e $g(x)=\cos x-$ e de algumas variações destas, mediante transformações nos gráficos das funções originais. 0 capítulo apresenta um expressivo número de exemplos, inclusive com uso do software GeoGebra (Figuras 2 e 3), sobre a função cosseno.

Compare inicialmente os gráficos das funções $g$ e $h$, dados respectivamente por $g(x)=\cos x$ e $h(x)=\cos (2 x)$, traçados em um mesmo sistema de coordenadas, com auxílio do GeoGebra. [Figura 2]

Observe que, ao "se comprimir na horizontal" o gráfico de $g$, obtém-se o gráfico de $h$ : o período de $g$ é $2 \pi$ e o período de $h$ é $\pi$.

A seguir, observe que o gráfico da função [...] $f(x)=1+\cos (2 x)$, é obtido a partir do gráfico de $h(x)=\cos (2 x)$ transladando-o uma unidade para cima, na vertical. [Figura 3] (ALMEIDA et al., 2016, p. 61)

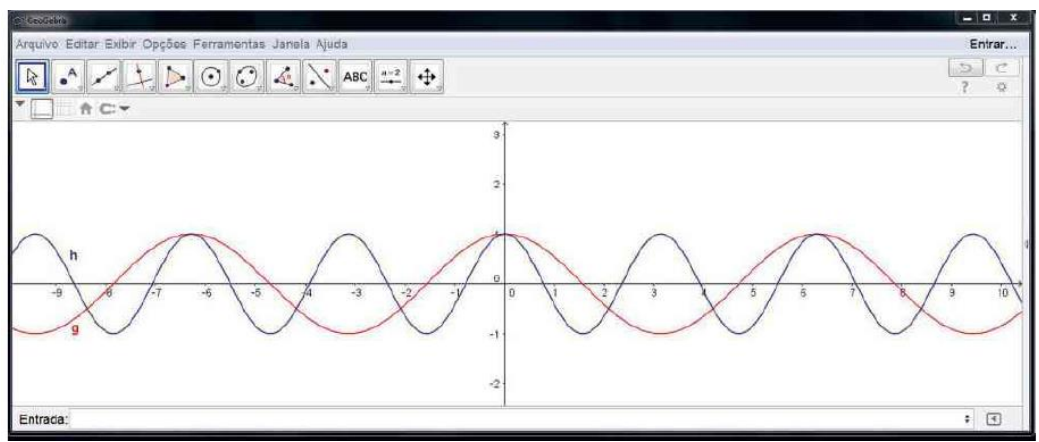

Figura 2: $g(x)=\cos x$ e $h(x)=\cos (2 x)($ ALMEIDA et al., 2016, p. 61) 


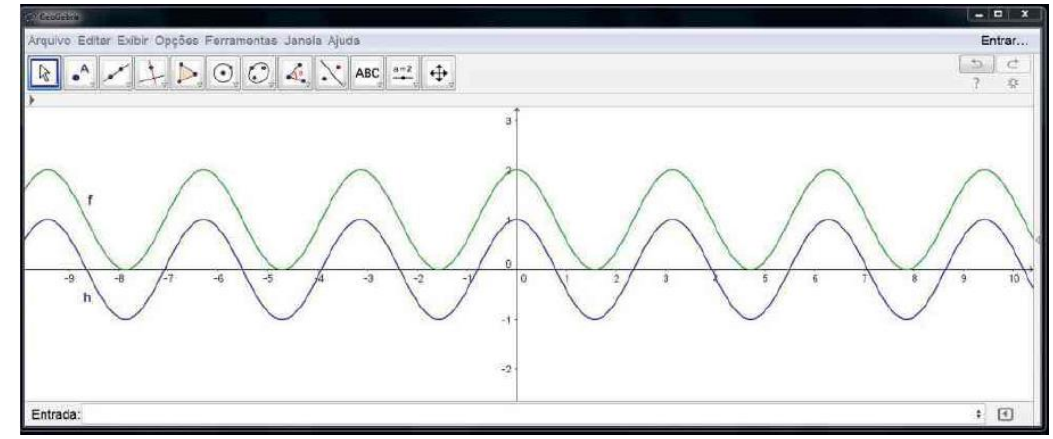

Figura 3: $f(x)=1+\cos (2 x)$ e $h(x)=\cos (2 x)$ (ALMEIDA et al., 2016, p. 61)

Ao final do capítulo, são propostos alguns exercícios de construção de gráficos.

No volume 1 da coleção Matemática: Contexto \& Aplicações, no capítulo referente às funções afim e modular, o autor apresenta 0 traçado de funções modulares mediante reflexões nas partes negativas de funções afins. Já no capítulo dedicado à função logarítmica, é apresentada a definição de logaritmo e suas propriedades elementares, e são feitas a construção do gráfico da função logarítmica e sua caracterização como inversa da função exponencial. 0 autor aproveita para destacar que o gráfico da função inversa de qualquer função bijetora é simétrico ao da função original em relação à reta $y=x$.

Já no volume 2 dessa coleção, no capítulo sobre funções trigonométricas, o autor aborda o traçado dos gráficos desse tipo de funções por meio de uma atividade no software GeoGebra. $\mathrm{O}$ autor apresenta um roteiro com o passo a passo da atividade, pedindo aos alunos que construam controles deslizantes para os parâmetros $a, b, c$ e $d$ da função $a+b \cdot \operatorname{sen}(c x+d)$; em seguida, pede para que eles interajam com os controles deslizantes criados, alterando o valor dos parâmetros, e indaga sobre a influência de cada parâmetro no gráfico da função.

$2^{\circ}$ passo: No campo Entrada de comando (situado na parte esquerda da tela) digite a função: $f(x)=a+b^{*} \operatorname{sen}\left(c^{*} x+d\right)$ e tecle "Enter". Observe que * significa a operação de multiplicação. Dessa forma você terá o gráfico da função $f(x)=a+b$. sen $(c x+d)$.

$3^{\circ}$ passo: Agora, você poderá observar significados importantes para os coeficientes $a, b, c$ e $d$. Para isso clique na bolinha do controle deslizante de $a$ e altere o seu valor (basta arrastar a bolinha para um dos lados). Observe o que acontece com o gráfico da senoide. Repita a operação para os controles deslizantes de $b, c$ e $d$ (utilize um controle deslizante por vez).

a) Qual é o efeito do parâmetro $a$ no gráfico da função?

b) Qual é o efeito do parâmetro $b$ no gráfico da função?

c) Qual é o efeito do parâmetro $c$ no gráfico da função?

d) Qual é o efeito do parâmetro $d$ no gráfico da função?

e) Utilizando o controle deslizante e fazendo $a=0, b=1, c=1$ e $d=1,6$, você 
terá aproximadamente 0 gráfico da função $f(x)=\operatorname{sen}\left(x+\frac{\pi}{2}\right)$. Esta última função é equivalente a uma função conhecida. Qual é essa função? (DANTE, 2017, p. 52)

Expôs-se nesta seção e nas anteriores a estrutura geral da apresentação do conteúdo de funções e gráficos feita pelos livros aqui analisados. Passar-se-á a apresentar a abordagem que eles fazem das matrizes e, na sequência, dos números complexos.

\section{Matrizes}

Dado um plano qualquer, introduzindo um sistema de coordenadas cartesianas nesse plano, qualquer transformação — de translação, reflexão, rotação ou homotetia — sofrida por uma figura nele pode ser descrita por uma função, cujo domínio é formado pelos pontos da figura original, e cuja imagem é estruturada pelos pontos da figura transformada. Essas funções, por sua vez, podem ser descritas mediante operações com matrizes. As matrizes, bem como suas operações básicas, em geral são apresentadas aos estudantes na segunda série do Ensino Médio

No volume 2 da coleção \#Contato Matemática, no capítulo dedicado à introdução às matrizes e determinantes, os autores optam por apresentar as transformações geométricas por meio de um exemplo, no qual eles expõem a resolução de um exercício. Nesse exercício, eles resolvem a rotação de um triângulo no plano, fazendo a rotação dos três vértices separadamente.

A rotação de um pixel de coordenadas $(x, y)$ em $\alpha$ graus, no sentido horário, em torno da origem, por exemplo, é feita pela multiplicação da matriz $\mathrm{P}=\left[\begin{array}{ll}x & y\end{array}\right]$ com a matriz $\mathrm{R}=\left[\begin{array}{cc}\cos \alpha & -\operatorname{sen} \alpha \\ \operatorname{sen} \alpha & \cos \alpha\end{array}\right]$, gerando uma nova matriz $\mathrm{P}^{\prime}=\mathrm{P} \cdot \mathrm{R}$, com as novas coordenadas $\left(x^{\prime}, y^{\prime}\right)$ do pixel.

Considere um triângulo $\mathrm{ABC}$ de vértices em $\mathrm{A}(3,2), \mathrm{B}(5,5)$ e $\mathrm{C}(7,0)$. Construa em um mesmo plano cartesiano os triângulos A'B'C' e A"B" $\mathrm{C}^{\prime \prime}$, obtidos pela rotação do $\triangle \mathrm{ABC}$ em $90^{\circ} \mathrm{e} \mathrm{em} 180^{\circ}$, respectivamente, em torno da origem, no sentido horário. (GARCIA e SOUZA, 2016a, p. 60)

Nessa perspectiva, os autores expõem brevemente o processo resolutivo e, na sequência, passam à resolução do exercício. Em seguida, são propostas algumas atividades referentes a matrizes e determinantes. Entre elas, há apenas uma tarefa sobre transformações geométricas.

Vimos que um ponto $\mathrm{P}(x, y)$ é rotacionado em $\alpha$ graus no sentido horário em torno da origem, pela multiplicação da matriz $\mathrm{P}=\left[\begin{array}{l}x y \\ y\end{array}\right]$ com a matriz $\mathrm{R}=$ $\left[\begin{array}{cc}\cos \alpha & -\operatorname{sen} \alpha \\ \operatorname{sen} \alpha & \cos \alpha\end{array}\right]$.

Dado o quadrilátero $\mathrm{ABCD}$, de vértices em $\mathrm{A}(1,1), \mathrm{B}(2,3), \mathrm{C}(4,4)$ e $\mathrm{D}(5,2)$, 
obtenha as coordenadas dos vértices do quadrilátero $\mathrm{A}^{\prime} \mathrm{B}^{\prime} \mathrm{C}^{\prime} \mathrm{D}^{\prime}$, obtido pela rotação em $270^{\circ}$ do quadrilátero $\mathrm{ABCD}$ em torno da origem, no sentido horário. Em seguida, construa os dois quadriláteros em um mesmo plano cartesiano.

Novamente, esse exercício configura a abordagem de ensinar para resolver problemas, uma vez que os alunos, para solucioná-lo, deverão aplicar o mesmo procedimento visto no exemplo aos quatro vértices do quadrilátero.

O volume 2 da coleção Matemática: ciência e aplicações abrange a teoria básica de matrizes. No final do respectivo capítulo, há uma seção de aplicação das matrizes à computação gráfica, em que os autores expõem as transformações de translação, rotação e escala.

As transformações geométricas no plano (ou transformações 2D - duas dimensões) são muito usadas pela computação gráfica para a construção de figuras e produção de imagens. Tais imagens podem ser percebidas nos efeitos especiais utilizados no cinema, na TV e nos sistemas multimídia em geral, além de servir de ferramenta de auxílio em várias áreas da atividade humana.

As três transformações básicas são: translação, rotação e escala. Vamos estudá-las, relacionando-as com a teoria das matrizes e com a Trigonometria.

Representaremos um ponto qualquer $\mathrm{P}(x, y)$ de uma figura pela matriz coluna $\mathrm{P}=$ $\left[\begin{array}{l}x \\ y\end{array}\right]$ e o ponto correspondente $\mathrm{P}^{\prime}\left(x^{\prime}, y^{\prime}\right)$, obtido pela transformação, por $\mathrm{P}^{\prime}=\left[\begin{array}{l}x^{\prime} \\ y^{\prime}\end{array}\right]$. Para cada transformação, vamos obter uma relação entre $\mathrm{P}$ e $\mathrm{P}^{\prime}$ por meio de uma matriz (M) de transformação. (ALMEIDA et al., 2016, p. 91)

Após essa apresentação, os autores explicam detalhadamente as três transformações citadas e as respectivas matrizes. Em particular, na parte sobre rotação, eles preocupam-se em deduzir a matriz de transformação, destacando a relação do assunto com a trigonometria. São formuladas apenas duas questões. A primeira refere-se à transformação de translação: "Qual é a matriz que transforma o triângulo de vértices $A(1,1), B(3,1)$ e $C(6,9)$ no triângulo de vértices $A^{\prime}(5,6), B^{\prime}(7,6)$ e $C^{\prime}(6,9)$ ?" (ALMEIDA et al., 2016, p. 91). Enquanto a outra questão diz respeito à transformação de escala: "Em um retângulo, as diagonais intersectam-se em seus pontos médios. Veja os pontos $\mathbf{M}$ e $\mathbf{M}^{\prime}$ [Figura 4]. Qual é a relação entre suas abscissas (e ordenadas) e as abscissas (e ordenadas) das extremidades das diagonais?" (ALMEIDA et al., 2016, p. 93).

Esses são dois exemplos de problemas que os alunos, para resolver, deverão mobilizar conhecimentos matemáticos diversos daqueles imediatamente estudados. 


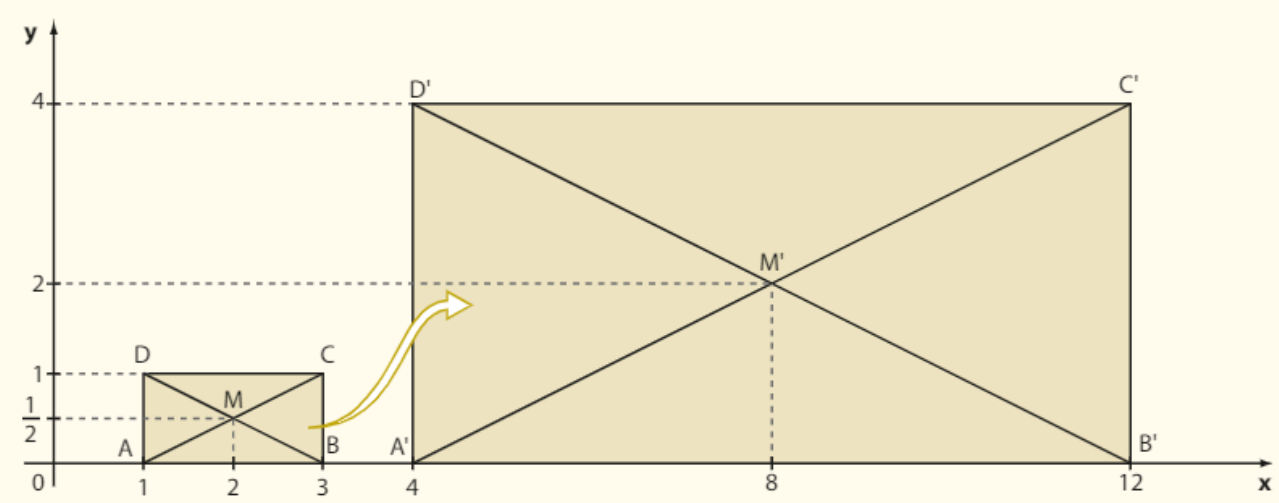

Figura 4: Questão sobre a transformação de escala (ALMEIDA et al., 2016, p. 93)

No volume 2 da coleção Matemática: Contexto \& Aplicações, é apresentada a teoria básica de matrizes e determinantes. Ao final do capítulo, a título de aplicação das operações adição e multiplicação de matrizes, são abordadas as transformações geométricas de translação, reflexão, rotação e mudança de escala (homotetias). Não são oferecidas definições dessas transformações; 0 autor se limita a explicá-las por intermédio de exemplos, como visto nas Figuras $5,6,7$ e 8 .

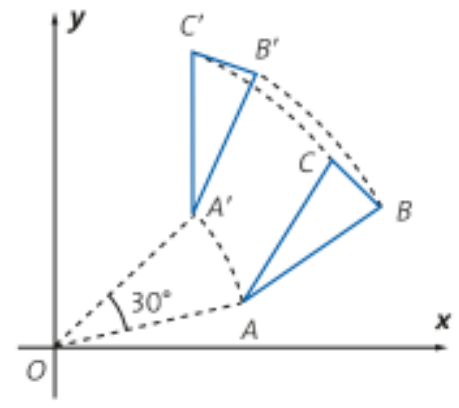

Figura 5: "Rotação do $\triangle \mathrm{ABC}$, de $30^{\circ}$ no sentido anti-horário, em torno da origem" (DANTE, 2017, p. 86)

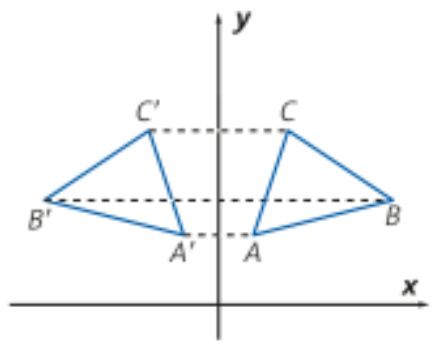

Figura 6: "Reflexão do $\triangle \mathrm{ABC}$ em relação ao eixo y" (DANTE, 2017, p. 86) 


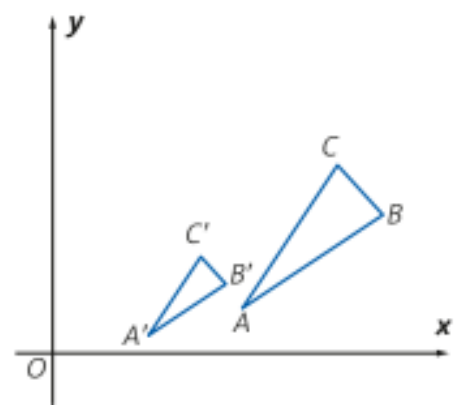

Figura 7: "Mudança de escala do $\triangle \mathrm{ABC}$ em 50\%" (DANTE, 2017, p. 86)

$\mathrm{Na}$ explicação dessa figura, o autor afirma: "Essa mudança de escala chama-se homotetia" (DANTE, 2017, p. 86).

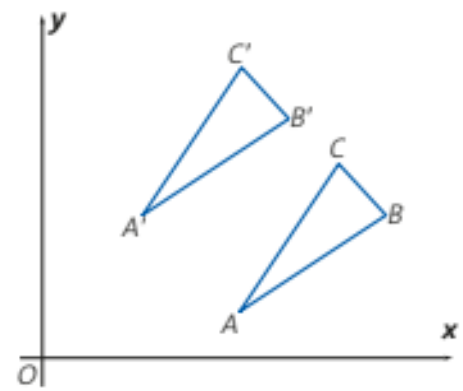

Figura 8: "Translação do $\triangle \mathrm{ABC}$ com 2 unidades para a esquerda e 2 unidades para cima" (DANTE, 2017, p. 86)

Em seguida, o autor detalha cada uma dessas transformações e mostra as operações com matrizes correspondentes. Novamente, o autor opta por apresentar um exemplo em cada um dos casos, ou seja, sugere uma explicação do conceito por meio da utilização de exemplos. Ao final de cada transformação, são propostos alguns exercícios. Na parte correspondente à translação, por exemplo, apenas dois exemplos são propostos:

Escreva no caderno o que significa cada uma das translações dadas pelas matrizes:
a) $\left(\begin{array}{l}2 \\ 3\end{array}\right)$
b) $\left(\begin{array}{c}3 \\ -1\end{array}\right)$
c) $\left(\begin{array}{l}-2 \\ -1\end{array}\right)$
d) $\left(\begin{array}{c}-2 \\ 4\end{array}\right)$

Copie o diagrama abaixo [Figura 9] em uma malha quadriculada. Translade o triângulo A de acordo com cada matriz coluna dada e desenhe o triângulo transladado.

a) $\left(\begin{array}{l}2 \\ 3\end{array}\right)$, dando origem ao triângulo $B$.

b) $\left(\begin{array}{l}-3 \\ -4\end{array}\right)$, dando origem ao triângulo $C$. 
c) $\left(\begin{array}{c}2 \\ -5\end{array}\right)$, dando origem ao triângulo $D$.

d) $\left(\begin{array}{l}-3 \\ -2\end{array}\right)$, dando origem ao triângulo $\mathrm{E}$.

e) Em cada caso, escreva a adição de matrizes correspondente. (DANTE, 2017, p. 87)

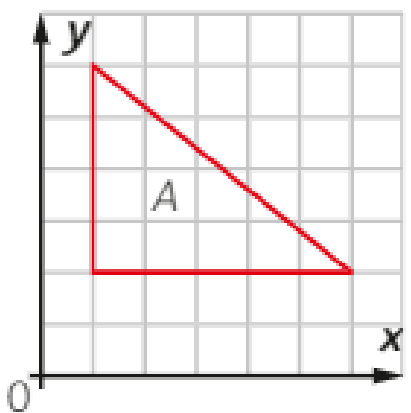

Figura 9: Exercício sobre translação (DANTE, 2017, p. 87)

É possível sugerir, nesses exercícios, a abordagem de ensinar para resolver problemas. Após terem lido a explicação sobre a translação via matrizes, os alunos são levados a pôr em prática o conhecimento previamente estudado por meio de exercícios repetitivos.

\section{Números complexos}

Os números complexos são introduzidos no Ensino Médio com o objetivo de sanar determinadas lacunas dos números reais, como a não existência de raízes quadradas reais de números reais negativos. Constrói-se, então, o conjunto dos números da forma $a+b i$, em que $a$ e $b$ são reais chamados, respectivamente, de parte real e parte imaginária, e $i$ é a unidade imaginária, tal que $i^{2}=-1$. Geometricamente, qualquer número complexo pode ser representado como um vetor no plano, com origem no ponto $(0,0)$ e extremidade no ponto $(a, b)$.

O comprimento do vetor é chamado de módulo do número complexo. E o ângulo formado pelo vetor com o eixo horizontal, no sentido anti-horário, denomina-se argumento do número complexo.

Alternativamente, um número complexo na forma $z=a+b i$ - chamada forma algébrica - pode ser representado na estrutura trigonométrica, que é: $z=|z|(\cos \theta+i$. $\operatorname{sen} \theta$ ), na qual $|z|=\sqrt{a^{2}+b^{2}}$ indica o módulo do número complexo e $\theta$ indica o argumento. Os números complexos e as transformações geométricas conectam-se porque, para multiplicar dois números complexos escritos na forma trigonométrica, deve-se multiplicar seus módulos e 
adicionar seus argumentos. Isso pode ser traduzido geometricamente numa roto-homotetia dos vetores que representam o número complexo.

$\mathrm{Na}$ abertura do capítulo 5 do terceiro volume da coleção \#Contato Matemática, os autores citam a obra do artista paulista Luiz Sacilotto, a título de motivação para o que será estudado.

Ao longo da história diferentes elementos matemáticos foram utilizados na composição de obras artísticas como a simetria, a ilusão de ótica, a geometria, a perspectiva e a razão áurea. Um exemplo de movimento artístico em que é notória a utilização da matemática é o Concretismo, cuja base são elementos geométricos. Nas pinturas concretistas, a atenção é voltada ao plano e às cores, alinhados ao rigor formal.

No Brasil, um dos representantes do Concretismo na pintura é Luiz Sacilotto (19242003). [...] Na tela abaixo, por exemplo, Sacilotto rotaciona e reproduz uma mesma figura, criando um interessante padrão visual. (GARCIA e SOUZA, 2016b, p. 145)

A obra citada é o quadro 0266, de Sacilotto, apresentado na Figura 10.

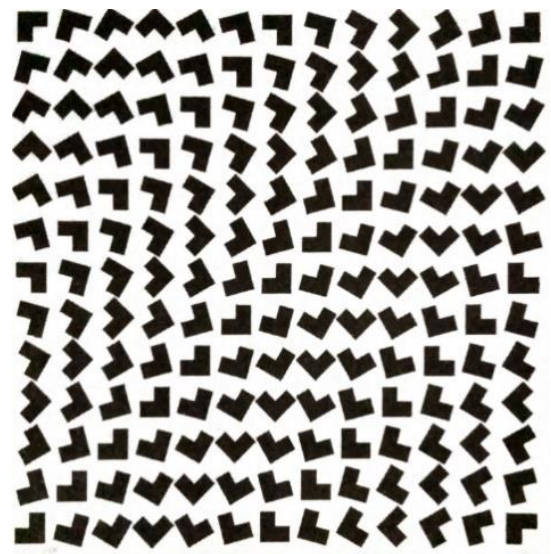

Figura 10: 0266 (GARCIA e SOUZA, 2016b, p. 145)

Em seguida, são formuladas algumas questões:

a) Cite características das pinturas concretistas.

b) Converse com um colega sobre o efeito visual gerado na tela acima.

c) Ao rotacionar uma imagem em $360^{\circ}$, no sentido horário, o que acontece com sua posição? (GARCIA e SOUZA, 2016b, p. 145)

Ao longo do capítulo, os autores introduzem os números complexos na forma algébrica, as operações básicas de adição, subtração, multiplicação e divisão, e passam à forma trigonométrica. Há uma seção do capítulo sobre números complexos e Geometria, em que se salienta a função da multiplicação desses números na descrição de rotações no plano. Eles não destacam as homotetias.

No final do capítulo, é sugerida uma atividade com a obra do já mencionado artista Luiz 
Sacilotto, que contém uma representação gráfica (Figura 11):

estudamos como 0 artista Luiz Sacilotto utilizava em algumas de suas obras padrões visuais com rotação de figuras. Veja ao lado [figura 7] a representação de uma figura da obra apresentada nessas páginas, no plano de Argand-Gauss.

Considere a multiplicação dos números complexos correspondentes aos pontos que compõem essa figura por $z=\cos \pi+i \operatorname{sen} \pi$. Em qual alternativa a figura corresponde à representação dos números complexos obtidos nessa operação? (GARCIA e SOUZA, 2016b, p. 167)

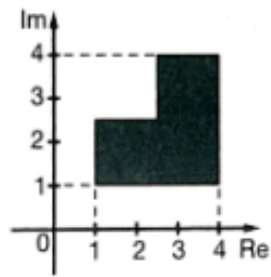

Figura 11: Questão sobre rotação (GARCIA e SOUZA, 2016b, p. 167)

Essa proposta está entre algumas tarefas sobre as rotações via multiplicação de números complexos.

Quanto à coleção Matemática: ciência e aplicações, os números complexos são abordados em seu volume 3 . Os autores contextualizam os números complexos e apresentam as operações, além de introduzirem a forma trigonométrica. Porém, não mencionam explicitamente a relação com as transformações geométricas.

O volume 3 da coleção Matemática: Contexto \& Aplicações, no capítulo sobre números complexos, tem uma seção de "Aplicação à Geometria", na qual o autor explica como aplicar a multiplicação de números complexos para rotacionar coordenadas no plano. Ou seja, dado um ponto $(a, b)$ no plano, para rotacioná-lo em $\alpha$ graus no sentido anti-horário, basta multiplicar o número complexo $a+b i$ pelo complexo $1(\cos \alpha+i \cdot \operatorname{sen} \alpha)$. A outra aplicação geométrica dos números complexos — as homotetias — não é abordada. Ao término da seção, o autor propõe apenas uma tarefa:

Qual número complexo, na forma trigonométrica, deve ser usado para se conseguir uma rotação de:
a) $45^{\circ}$ anti-horário?
b) $180^{\circ}$ anti-horário?
c) $90^{\circ}$ horário?

Nessa tarefa, sugere-se a abordagem de ensinar para resolver problemas, em que os 
alunos são levados a reproduzir imediatamente a técnica recém estudada.

\section{Resultados e considerações finais}

Em todas as coleções analisadas, constatou-se a presença das transformações geométricas, seja para contribuir com a resolução a resolução de determinados problemas como o traçado do gráfico de funções -, seja para introduzir a aplicação de outros conteúdos estudados, como matrizes ou números complexos. No entanto, em ambos os casos, as transformações geométricas apareceram como "coadjuvantes" e foram "ofuscadas" pelos assuntos principais. Com isso, o tratamento dispensado a elas é ainda superficial, carecendo de ampliação de representações geométricas e de exemplos de aplicações a outras áreas do conhecimento humano para a visualização dos conceitos relativos a esse conteúdo.

Além disso, as tarefas encontradas nos livros apresentaram lacunas - a maioria era composta por exercícios, e não problemas. $E$, entre os problemas propostos, identificou-se que a tendência é uma sugestão de ensinar para resolver problemas, em vez de ensinar via resolução de problemas. $O$ Quadro 2 apresenta uma síntese dessas informações.

Quadro 2: Síntese dos livros analisados

\begin{tabular}{|c|c|c|c|}
\hline Coleção & Funções e gráficos & Matrizes & Números complexos \\
\hline \#Contato Matemática & $\begin{array}{l}\text { As transformações } \\
\text { aparecem no traçado } \\
\text { de gráficos, } \\
\text { principalmente no das } \\
\text { funções afim, modular } \\
\text { e trigonométrica. }\end{array}$ & $\begin{array}{l}\text { São apresentadas de } \\
\text { passagem, a título de } \\
\text { exemplo. Os autores } \\
\text { resolvem um exercício } \\
\text { de rotacionar um } \\
\text { triângulo no plano. }\end{array}$ & $\begin{array}{c}\text { A rotação aparece } \\
\text { como aplicação da } \\
\text { multiplicação de } \\
\text { números complexos na } \\
\text { forma trigonométrica. }\end{array}$ \\
\hline $\begin{array}{c}\text { Matemática: ciência e } \\
\text { aplicações }\end{array}$ & $\begin{array}{l}\text { Aparecem, sobretudo, } \\
\text { no estudo das funções } \\
\text { trigonométricas. Há } \\
\text { exemplos com o } \\
\text { software GeoGebra. }\end{array}$ & $\begin{array}{l}\text { Aparecem a título de } \\
\text { exemplo, mas a } \\
\text { explicação oferecida } \\
\text { pelos autores é } \\
\text { bastante detalhada. } \\
\text { Não são propostas } \\
\text { tarefas. }\end{array}$ & Não são comentadas. \\
\hline $\begin{array}{l}\text { Matemática: Contexto } \\
\text { \& Aplicações }\end{array}$ & $\begin{array}{l}\text { Aparecem no estudo } \\
\text { da função modular, } \\
\text { cujo gráfico pode ser } \\
\text { obtido refletindo as } \\
\text { partes negativas da } \\
\text { função. Também estão } \\
\text { presentes no estudo } \\
\text { das funções } \\
\text { trigonométricas, em }\end{array}$ & $\begin{array}{l}\text { As transformações } \\
\text { geométricas aparecem } \\
\text { como aplicação de } \\
\text { matrizes, porém são } \\
\text { incorporadas ao texto } \\
\text { principal, incluindo } \\
\text { exercícios. }\end{array}$ & $\begin{array}{c}\text { A rotação aparece } \\
\text { como aplicação da } \\
\text { multiplicação de } \\
\text { números complexos na } \\
\text { forma trigonométrica. }\end{array}$ \\
\hline
\end{tabular}




\begin{tabular}{|c|c|c|c|}
\hline & $\begin{array}{c}\text { que o autor sugere 0 } \\
\text { uso do software } \\
\text { GeoGebra. }\end{array}$ & \\
\hline
\end{tabular}

Fonte: Dados da Pesquisa

Em relação ao papel reservado ao professor, percebe-se que os livros analisados não abordam ou sugerem ações a serem empreendidas pelos professores. Isso implica dizer que as obras são sucintas e "autossuficientes", não salientam o trabalho do professor. De acordo com Silva (1996, p. 11),

a intermediação desses livros, na forma de costume, dependência e/ou "vício", caracteriza-se como um fator mais importante do que o próprio diálogo pedagógico, que é ou deveria ser a base da existência da escola. Resulta desse lamentável fenômeno uma inversão ou confusão de papéis nos processos de ensinoaprendizagem, isto é, ao invés de interagir com o professor, tendo como horizonte a (re)produção do conhecimento, os alunos, por imposição de circunstâncias, processam redundantemente as lições inscritas no livro didático adotado.

Além disso, trata-se de um problema antigo. Platão (2000, p. 122-123), no diálogo Fedro, já registrava um comentário de Sócrates contra a obediência cega aos livros:

O maior inconveniente da escrita parece-se, caro Fedro, se bem julgo, com a pintura. As figuras pintadas têm atitudes de seres vivos mas, se alguém as interrogar, manterse-ão silenciosas, o mesmo acontecendo com os discursos: falam das coisas como se estas estivessem vivas, mas se alguém os interroga, no intuito de obter um esclarecimento, limita-se a repetir sempre a mesma coisa. Mais: uma vez escrito, um discurso chega a toda parte, tanto aos que o entendem como aos que não podem compreendê-lo e, assim, nunca se chega a saber a quem serve e a quem não serve.

Em outras palavras, para a utilização do livro didático de forma mais significativa, sugerese a integração de tarefas que promovam a exploração e a investigação do conteúdo de transformações geométricas pode ampliar as possibilidades de diálogo entre alunos e professores. Em pesquisas futuras, toma-se como fundamental promover a elaboração de tarefas com a incorporação de materiais manipuláveis e softwares de Geometria Dinâmica que possam ser debatidas no âmbito dos cursos de formação inicial e continuada de professores.

\section{Referências}

ALLEVATO, Norma Suely Gomes; ONUCHIC, Lourdes de la Rosa. Ensino-AprendizagemAvaliação de Matemática: por que Através da Resolução de Problemas? In: ALLEVATO, Norma Suely Gomes; JUSTULIN, Andresa Maria; NOGUTI, Fabiane Cristina Höpner; ONUCHIC, Lourdes de la Rosa (Org.). Resolução de Problemas: teoria e prática. Jundiaí: Paco Editorial, 2014. p. 3251. 
ALMEIDA, Nilze de; DEGENSZAJN, David; DOLCE, Osvaldo; IEZZI, Gelson; PÉRIGO, Roberto. Matemática: ciência e aplicações. v. 2, 9. ed. São Paulo: Saraiva, 2016.

BOYER, Carl Benjamin. História da Matemática. Tradução de Elza Furtado Gomide. São Paulo: Edgar Blücher, 1974.

BRASIL. Ministério da Educação. Secretaria de Educação Básica. Base Nacional Comum Curricular. Ensino Médio. Brasília: MEC/SEB, 2018.

BROLEZZI, Antonio Carlos. Criatividade e resolução de problemas. São Paulo: Livraria da Física, 2013.

DANTE, Luiz Roberto. Matemática: contexto \& aplicações. v. 2, 3. ed. São Paulo: Ática, 2017.

DELMONDI, Natalia Nascimben; PAZUCH, Vinícius. Um panorama teórico das tendências de pesquisa sobre 0 ensino de transformações geométricas. Revista Brasileira de Estudos Pedagógicos, Brasília, v. 99, n. 253, p. 661-686, set./dez. 2018.

ECHEVERRÍA, María del Puy Pérez; POZO, Juan Ignacio. Aprender a resolver problemas e resolver problemas para aprender. In: $\mathrm{POZO}$, Juan Ignacio. (Org.). A solução de problemas: aprender a resolver, resolver para aprender. Tradução de Beatriz Affonso Neves. Porto Alegre: ArtMed, 1998. p. 13-42.

GARCIA, Jacqueline; SOUZA, Joamir. \#Contato Matemática. v. 3. São Paulo: FTD, $2016 \mathrm{~b}$.

GARCIA, Jacqueline; SOUZA, Joamir. \#Contato Matemática. v. 2. São Paulo: FTD, 2016a.

LIMA, Katia; JANUARIO, Gilberto. Princípios de integração de valores culturais ao currículo e a organização dos conteúdos em livros didáticos de Matemática. Educação Matemática Debate, Montes Claros, v. 1, n. 1, p. 76-98, jan./abr. 2017.

OLIVEIRA, Gerson Pastre de.; LIMA, Nilo Silveira Monteiro de. Estratégias didáticas com tecnologias na formação continuada de professores de Matemática: uma investigação sobre homotetia. Educação Matemática Pesquisa, São Paulo, v. 20, n. 1, p. 385-418, jan./abr. 2018.

PLATÃo. Fedro ou da Beleza. Tradução de Pinharanda Gomes. 6. ed. Lisboa: Guimarães Editores, 2000.

SAVIANI, Demerval. História das ideias pedagógicas no Brasil. 4. ed. Campinas: Autores Associados, 2013.

SILVA, Daniel Romão da. Livro didático de Matemática: lugar histórico e perspectivas. 2010. $152 f$. Dissertação (Mestrado em Educação) - Faculdade de Educação, Universidade de São Paulo. São Paulo.

SILVA, Ezequiel Theodoro da. Livro didático: do ritual de passagem à ultrapassagem. Em Aberto, Brasília, v. 16, n. 69, p. 11-15, jan./mar. 1996

ZILBERMAN, Regina. A literatura infantil na escola. 10. ed. São Paulo: Global, 2003. 